\title{
Monoclonal Antibodies Which Distinguish Certain Classes of Neuronal and Supporting Cells in the Nervous Tissue of the Nematode Caenorhabditis Elegans ${ }^{1}$
}

\author{
HARUMASA OKAMOTO² AND J. NICHOL THOMSON \\ Medical Research Council Laboratory of Molecular Biology, Hills Road, Cambridge, CB2 2QH, England
}

\begin{abstract}
Monoclonal antibodies were generated using mice immunized with total homogenates of Caenorhabditis elegans adults or early larvae. Two of them were shown to distinguish a certain class of neuronal or supporting cells in the nervous tissue of this animal. Their histological speciflcities were studied in detail by indirect immunofluorescence on a whole mount preparation of animal head (or tail); for one of the antibodies further analysis was done by immunoelectron microscopy with the aid of a colloidal gold probe. An application of this antibody to a mutant of $C$. elegans is also described.
\end{abstract}

Hybridoma technology has been successfully applied in a variety of animal species to generate monoclonal antibodies that can distinguish different subsets of neurons or related structures (Barnstable, 1980; Cohen and Selvendran, 1981; Vulliamy et al., 1981; Zipser and McKay, 1981; Fujita et al., 1982; Hawkes et al., 1982a, b; McKay and Hockfield, 1982; Sternberger et al., 1982; Wood et al., 1982; reviewed by McKay, 1983). One of the ultimate goals of these studies is to reveal the cellular and molecular mechanisms by which the development of neuronal circuitry and its functional output, animal behavior, are regulated. The small, free-living nematode Caenorhabditis elegans seems to be another promising experimental organism in which to approach these problems, because its total complement of neurons is extremely small (302), yet it displays a rich variety of behaviors (reviewed by Ward, 1979). In addition, the detailed structure and synaptic connectivity of the entire." nervous system has been elucidated from serial section electron micrographs (Ward et al., 1975; Ware et al., 1975; Albertson and Thomson, 1976; White et al., 1976, 1983; Hall, 1977; Sulston et al., 1980; J. G. White, E. Southgate, J. N. Thomson, and S. Brenner, manuscript in preparation). An extensive genetic analysis is being undertaken on this

Received May 22, 1984; Revised September 14, 1984;

Accepted September 20, 1984

\footnotetext{
${ }^{1}$ We wish to thank John G. White, Edward M. Hedgecock, and Donna Albertson for their helpful suggestions and discussions throughout this work, Iva Greenwald for her suggestions, and John E. Sulston for his critical reading of the manuscript. Thanks are also due to Michael Wilcox, Richard Smith, and Rob White for their help and suggestions about the hybridoma technology, and to John Kilmartin for his help on the immuno-gold stairing procedure. H. O. was supported by a British Council Scholarship and a European Molecular and Biological Organization long-term fellowship.

${ }^{2}$ To whom correspondence should be sent, at his present address: Department of Neurobiology, Institute of Brain Research, School of Medicine, University of Tokyo, Hongo 7-3-1, Bunkyo-ku, Tokyo 113, Japan.
}

animal (Brenner, 1974; Herman and Horvitz, 1980), and a wide variety of behavioral mutants have been isolated (Ward, 1973; Dusenbery et al., 1975; Hedgecock and Russell, 1975; Lewis and Hodgkin, 1977; Chalfie and Sulston, 1981).

The aim of the present work is to generate monoclonal antibodies to $C$. elegans nervous tissue and determine their histological specificity. For this purpose we developed a staining procedure for preparation of whole mounts of animal heads (or tails in some cases) that facilitates the identification of the stained cells at the light

TABLE I

Summary of cell or tissue specificity of four monoclonal antibodies that have affinity for $C$. elegans nervous tissue

In a typical fusion experiment using adult animals as immunogen. about half of the original microwells (total, 432) gave growing hybridoma colonies. About half of the culture supernatant tested gave positive signals. Their cell or tissue specificity was as follows (the number in parentheses is that of repeats): 1CB4-type specificity (35), 1CB3-type specificity (2), 3NB6-type specificity (1), intestine (17), cuticle (14), sperm (5), pharynx (4), muscle (4), ovary (4), egg shell (2), excretory cell (1), nuclei and spermatheca (1), intestine and pharynx (1), and not identified (12).

\begin{tabular}{|c|c|}
\hline $\begin{array}{c}\text { Monoclonal } \\
\text { Antibodies }\end{array}$ & Specificity \\
\hline $1 \mathrm{CB} 4$ & $\begin{array}{l}\text { Presumptive chemosensory neurones (inner labial } 2 \text {, } \\
\text { cephalic companion cell, and possibly ray neu- } \\
\text { rone B). } \\
\text { Intestine and sperm. }\end{array}$ \\
\hline $1 \mathrm{CB3}$ & $\begin{array}{l}\text { Supporting cells (amphid sheath cell and a compo- } \\
\text { nent of the phasmids). } \\
\text { Intestine. }\end{array}$ \\
\hline $1-2 F 2^{a, b}$ & Processes in the nerve ring (possibly RME). \\
\hline $3 \mathrm{NB}^{b}$ & Mechanosensory neurones and pharyngeal muscle. \\
\hline
\end{tabular}

${ }^{a}$ Obtained in a fusion experiment using juveniles as immunogen.

${ }^{b}$ Detailed studies are not presented in this paper.

microscopic level; the procedure will also be useful for the rapid screening of mutants that have defects in the neuronal circuitry among those displaying a behavioral phenotype. Application of the colloidal gold technique to ultrathin sections for electron microscopy to determine the specificity of one of the monoclonal antibodies obtained (Roth et al., 1978; de May et al., 1981) is also described in detail.

\section{Materials and Methods}

Generation of monoclonal antibodies. BALB/C mice were immunized with total homogenates from adults or early larvae of Caenorhabditis elegans (three intraperitoneal injections and one intravenous injection over a period 
of a month). Hybridomas were generated as described previously (Wilcox et al., 1981), using NSO myeloma cells that were kindly supplied by C. Milstein (M. Clark, B. W. Wright, and C. Milstein, unpublished results, quoted in Galfré and Milstein, 1981). The culture supernatants were screened by indirect immunofluorescence for the presence of antibodies reacting with the nervous tissue of $C$. elegans. In order to overcome penetration problems in animals protected with a tough impermeable cuticle, we used a squashing procedure that yields flattened half-animals attached to glass slides for screening (D. Albertson, J. Sulston and E. Hedgecock personal communication). In short, densely settled worms were pipetted onto gelatin-subbed
Figure 1. Immunofluorescent staining of a whole mount hermaphrodite head preparation with the monoclonal antibody 1CB4: a left side view. $A$ to $D$ represent four successive focal planes through the specimen; $E$ is a diagram showing the relation of the stained cells (thin drawing) to the gross anatomical structure of the animal head (thick drawing). In $E$, only three of the stained cells on the left side are shown. a to $d$, Nuclear stain with Hoechst 33258 in the same focal planes as $A$ to $D$. Bar, $20 \mu \mathrm{m}$.
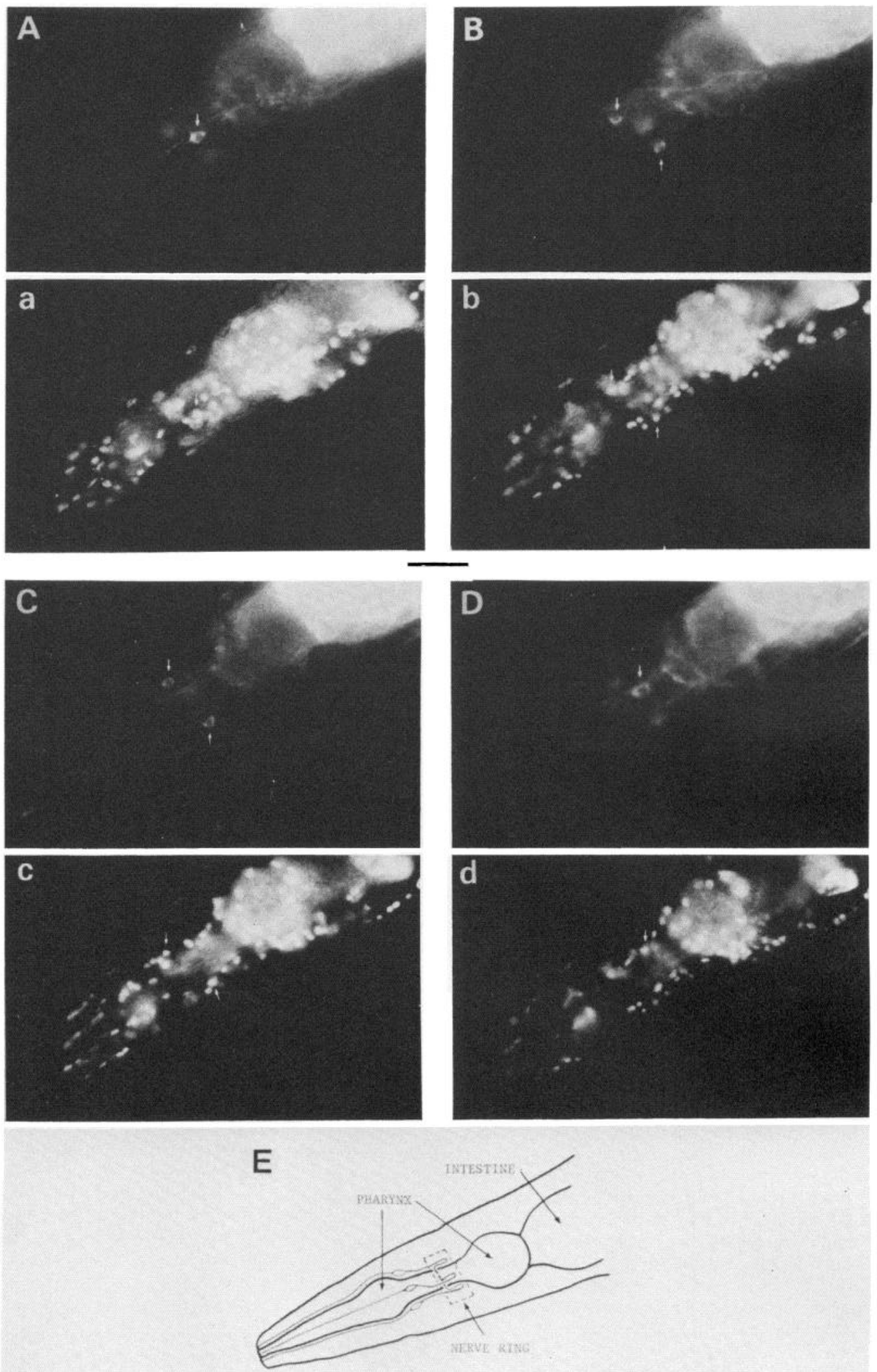
slides in $1-\mu l$ drops, and a second subbed slide was lowered on top; the two slides were clamped, frozen on dry ice, and then pried apart with a razor blade. The specimens were fixed by sequential immersion in cold $\left(-20^{\circ} \mathrm{C}\right)$ methanol and acetone. About half of the culture supernatants tested gave the positive signals (see Table I legend), indicating that the procedure including the methanol/acetone step might not be destructive for a number of antigens. Hybridomas of interest were cloned as described (Wilcox et al., 1981), and monoclonal antibodies produced by them were concentrated by ammonium sulfate precipitation ( $50 \%$ cut).

Whole mount preparation and staining of animal heads or tails. Young adults were washed off a culture plate and incubated with $1 \mathrm{ml}$ of 0.5 to $2 \%$ paraformaldehyde in phosphate-buffered saline (PBS) in a test tube overnight at $0^{\circ} \mathrm{C}$. After the prefixed animals had been washed with M9 buffer (Brenner, 1974) several times, a portion was transferred onto a small agar plate. Twenty animals were picked and placed in a $5-\mu$ l drop of proteinase $\mathrm{K}$ solution ( 2 $\mathrm{mg} / \mathrm{ml})$, prepared by 5 -fold dilution of a stock solution $(10 \mathrm{mg} / \mathrm{ml})$ of the proteolytic enzyme (Boehringer-Mannheim) in Tris- $\mathrm{Cl}(10 \mathrm{mM}, \mathrm{pH} 8.0)$ with M9 buffer, on a microscope slide subbed with gelatin (Gall and Pardue, 1971). The slide was kept in a humidified chamber (an inverted agar plate) during the picking operation to minimize evaporation. The animals on the slide were subsequently cut behind the pharynx (for head preparation) or the anus (for tail preparation) with a surgical blade. Again, to minimize evaporation during the cutting operation, the slide was kept on a glass Petri plate filled with ice-water. The incubation with proteinase $\mathrm{K}$ then continued in a humidified chamber for 15 to $30 \mathrm{~min}$ at $20^{\circ} \mathrm{C}$. A $12 \times 12 \mathrm{~mm}$ coverslip was placed gently on top of the incubated drop and the slide was immediately frozen on dry ice. After $20 \mathrm{~min}$, the coverslip was pried off with a razor blade
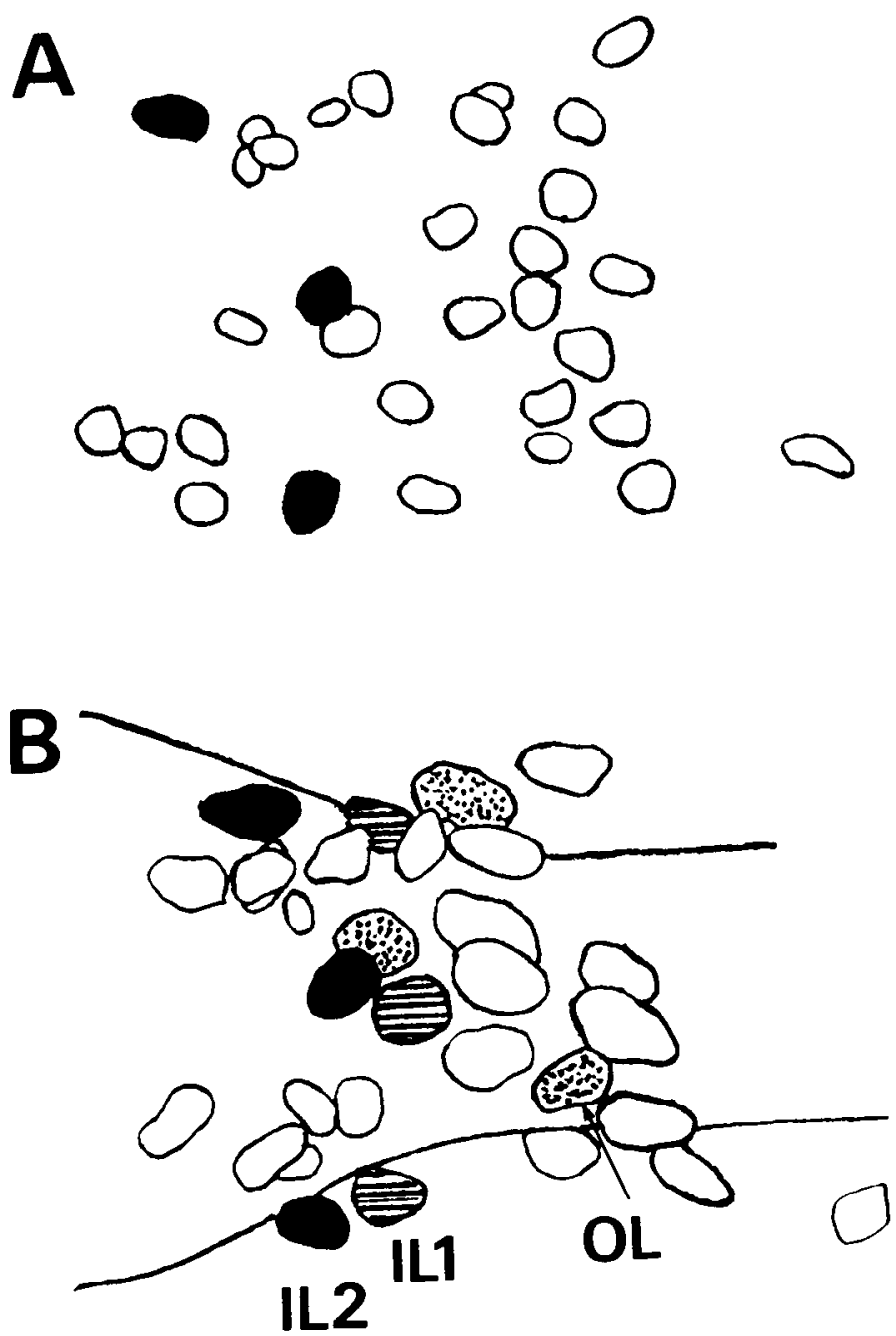

Figure 2. Relative nuclear position of the neuronal and supporting cells in front of the nerve ring, left lateral aspect. A, Deduced from Hoechst 33258 staining of the whole mount preparation shown in Figure 1. $B$, Deduced from serial section electron micrographs (J. G. White, E. Southgate, J. N. Thomson, and $\mathrm{S}$. Brenner, manuscript in preparation). and the slide was placed in methanol at $-20^{\circ} \mathrm{C}$ for $1 \mathrm{~min}$ followed by acetone at $-20^{\circ} \mathrm{C}$ for $2 \mathrm{~min}$. Slides were half-dried in air and then transferred to a humidified chamber for rehydration. After 5 to $10 \mathrm{~min}$, the excess rehydration solution was wiped off the slide and $100 \mu \mathrm{l}$ of PBS containing $10 \mathrm{mg} / \mathrm{ml}$ of bovine serum albumin and $1 \mathrm{~mm}$ phenylmethylsulfonyl fluoride were added to the specimens. The head or tail portions were then transferred into a well on a Multitest slide (eight-well, Flow Laboratories) with a finely drawn pipette and rinsed with $20 \mu \mathrm{l}$ of the above solution three times (each for at least 15 $\mathrm{min}$ at room temperature). Antibody solution $(20 \mu \mathrm{l})$ containing $1 \mathrm{mg} / \mathrm{ml}$ of bovine serum albumin (in the presence or absence of $0.2 \%$ saponin, depending on the antigen to be examined) was pipetted onto the specimens and the slide was placed in a humidified chamber overnight at room temperature. The specimens were washed three times (each for $15 \mathrm{~min}$ ) with PBS and then incubated with fluorescein isothiocyanate-conjugated second antibody solution for $1 \mathrm{hr}$ at room temperature. The slide was then rinsed as before except that the final washing solution included $0.5 \mu \mathrm{g} / \mathrm{ml}$ of Hoechst 33258 (Albertson et al., 1978) to visualize nuclei in the whole mount preparation.

Immunoelectron microscopy with the colloidal gold probe. A rabbit antimouse lgG (Miles Laboratories) was affinity purified and coupled to $50-\AA$ colloidal gold particles. The affinity resin consisted of a monoclonal antibody, $1 \mathrm{CB} 4$, that had been partially purified on DE52-cellulose $(0$ to $0.2 \mathrm{M} \mathrm{NaCl}$ gradient elution in $50 \mathrm{~mm}$ Tris-Cl, $\mathrm{pH} 8.5$ ), coupled to $\mathrm{CNBr}$-Sepharose 4B (Pharmacia). The coiloidal gold particles (the kind gift of Dr. John Kilmartin) were conjugated with the affinity-purified rabbit anti-mouse $\operatorname{lgG}$ according to the procedure published by de May et al. (1981) and Dr. Kilmartin's unpublished observations. The animals were fixed in $3 \%$ glutaraldehyde (in $0.1 \mathrm{M}$ PIPES pH 6.94; 1,4-piperazinediethanesulfonic acid) for $1 \mathrm{hr}$ at room temperature, embedded in Araldite, and thin-sectioned as described previously (Ward et al., 1975). The grids with sections were floated on a droplet ( 25 to $50 \mu l)$ of the antibody 1CB4 for 1 to $2 \mathrm{hr}$ at room temperature. After three washes in saline (each $10 \mathrm{~min}$ ) and one in distilled water, the grids were dried and floated on a droplet (5 to $10 \mu \mathrm{l})$ of the colloidal gold coupled second-layer antibody for 0.5 to $1 \mathrm{hr}$ at room temperature. After three washes in saline and one in distilled water, the grids were dried and stained with uranyl acetate and lead citrate in the conventional way. Observations were made using an AEI EM802 electron microscope.

\section{Results and Discussion}

\section{Generation of antibodies}

The nervous tissue of $C$. elegans consists of 302 neurons (in the hermaphrodite; 381 in the male) and 56 supporting cells (in the hermaphrodite; 92 in the male) (White et al., 1983; J. G. White, E. Southgate, J. N. Thomson, and S. Brenner, manuscript in preparation). The 302 neurons have been put into 118 classes that were defined on the basis of morphology, ultrastructure, and patterns of synaptic contact; the largest class has 13 members, but many have only a single member (White et al., 1983). The supporting cells are classified according to their associated neurons.

Because the worm is so small ( $1 \mathrm{~mm}$ long), it was impractical to dissect out enough of the nervous tissue for immunization. Therefore, BALB/C mice were immunized with a total homogenate of adult animals or juveniles just after hatching; in the latter case the head represents a larger proportion of the animal. Hybridoma culture medium was screened for the presence of interesting antibodies by applying the conventional indirect immunofluorescent staining procedure to squashed animals (see "Materials and Methods" for detail).

Four different types of hybridoma cell lines have so far been obtained which produce antibodies that have affinity to $C$. elegans nervous tissue. All of them have been recovered as monoclonal cell lines. The cell or tissue specificity of these four types of monoclonal antibodies is summarized in Table I. Three of them have some affinity to tissues other than nervous tissue, but they can all distinguish certain classes of neuronal or supporting cells. Some detailed studies on the specificity of the monocional antibodies, 1CB4 and 1CB3, will be described below.

\section{Cell or tissue specificity of monoclonal antibodies}

Although the squashed preparations are convenient for the initial screening of antigen distribution, they are inadequate for the definite 
identification of the antibody-bound cells. For this purpose we have developed a procedure for staining cells in whole mount preparations of the animal head (or tail) (see "Materials and Methods" for detail). The critical step is proteinase $\mathrm{K}$ treatment that is employed to overcome penetration problems in the prefixed animals; insufficient action of the enzyme resulted in a poor staining pattern with rather high background, whereas excessive enzyme treatment caused distortion of the gross structure with high background staining again and loss of antigenic sites in most cases.

By referring to serial section reconstructions (White et al., 1983; J. G. White, E. Southgate, J. N. Thomson, and S. Brenner, manuscript in preparation), we could ascertain which cells stained with the respective monoclonal antibodies. Usually, the clue lay in the relative positions of the nuclei, which were visualized by counterstaining with Hoechst 33258 (see below for detail).

Specificity of 1CB4 in hermaphrodite nervous tissue. In Figure 1, $A$ to $D$, a whole mount preparation of the head (hermaphrodite) is stained with the monoclonal antibody 1CB4; four different focal planes are shown. Besides the intensive staining of the intestine (refer to Fig. $1 E$ for gross anatomy), there are six cell bodies stained clearly in these planes just behind the front bulb of the pharynx (arrows in Fig. 1, $A$ to $D$ ). The processes are also stained extending from the cell bodies forward, up to the very tip of the animal head (out of picture), and backward. By changing focal plane, we were able to trace the processes running backward into the nerve ring, a circular bundle of processes that surrounds the pharynx. It is a region to which many neurons send processes and where most of the sensory integration takes place (White et al., 1983). Since only the neurons have processes in the nerve ring, the stained cells in Figure $1, A$ to $D$, are not supporting cells but neurons.

The total number of cells stained with 1 CB4 is six in the hermaphrodite (for the male, see the next section) for several other preparations examined. They are arranged symmetrically around the pharynx. Three different classes of neurons have been assigned in this region, which have 6-fold symmetry: inner labial 1 (IL1), inner labial 2 (IL2), and outer labial (OLL plus OLQ) (Ward et al., 1975; J. G. White, E. Southgate, J. N. Thomson, and S. Brenner, manuscript in preparation). We had to determine which one of these three classes was stained with 1CB4. In Figure 1 ( $a$ to $d$ ) the nuclei in the whole mount specimen are visualized with Hoechst 33258. Since

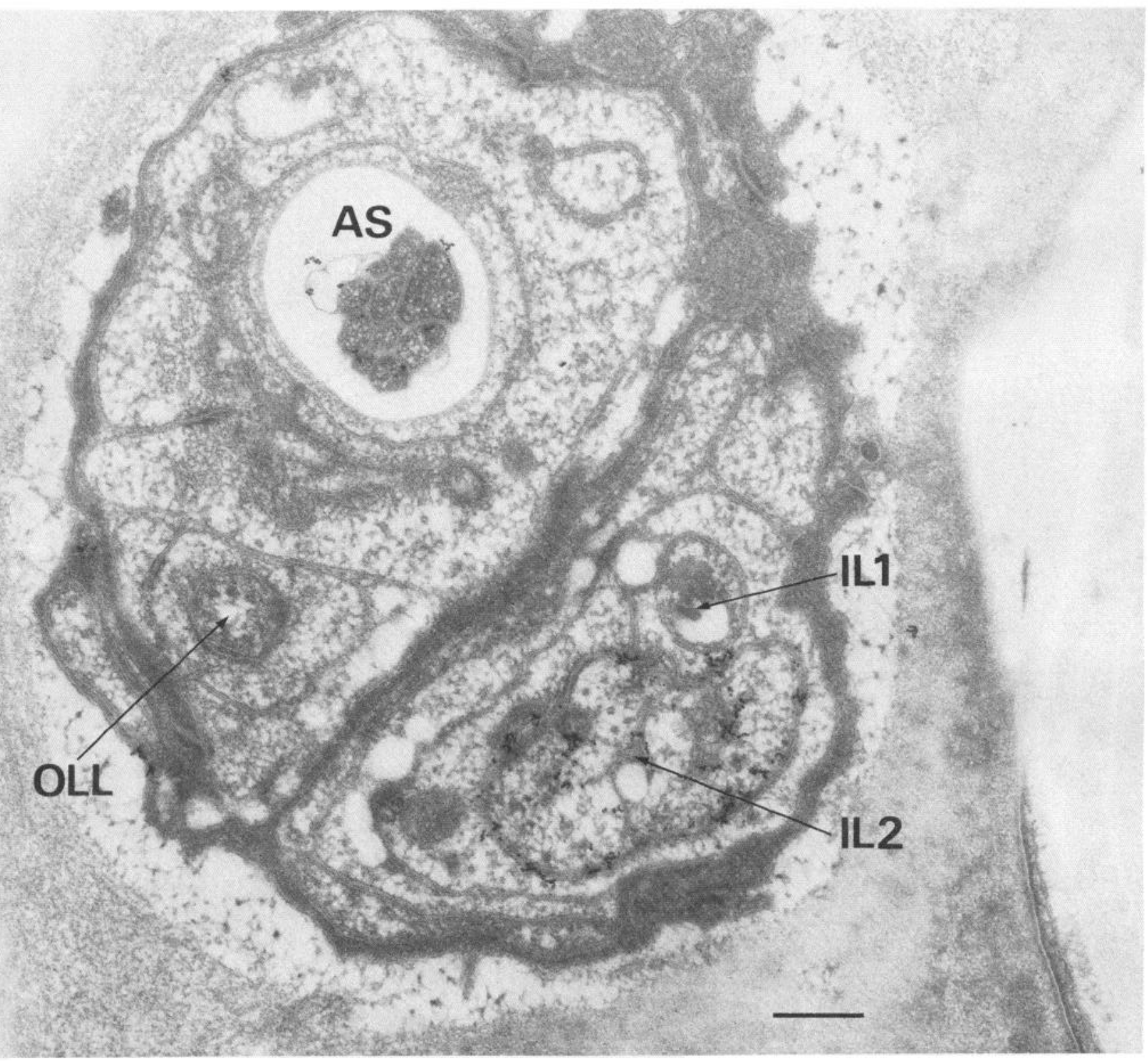

Figure 3. Immuno-gold staining of the process of an IL2 neuron. The transverse section was cut near the tip of the head and stained with a colloidal gold probe as described under "Materials and Methods." The right lateral side is shown. Bar, $0.2 \mu \mathrm{m}$. Note the colloidal gold particles in the IL2 process. 
the pictures were taken at the same focal planes as the immunofluorescent staining, we can easily identify the nuclei of the six neurons labeled with 1CB4 (marked by arrows in Fig. 1, a to d). The arrangement of the neuronal and supporting cell nuclei in front of the nerve ring (left lateral aspect in this particular case) is deduced from Figure 1, $a$ and $b$ (and pictures taken at intermediate focal planes, not shown), and is illustrated in Figure $2 A$. It is compared to the nuclear arrangement deduced from serial section electron micrographs (Fig. 2B, White et al., in preparation). The nuclei of the lefthand three of the six stained cells (Fig. $2 A$, shading) appear to correspond to those of the IL2s in Figure 2B. Similar analyses were done on several other whole mount preparations, and we conclude from these light microscopic studies that 1CB4 has a strong affinity for IL2, presumptive chemosensory neurons.

The same conclusion was drawn from analysis at the electron microscopic level using a colloidal gold/second antibody conjugate to visualize the antigen distribution. Several serial transverse sections of an Araldite-embedded specimen were cut near the tip of the head; it is the most convenient place for the identification of each neuronal process. They were incubated with the antibody 1CB4 and subsequently with a second-layer antibody conjugated with colloidal gold particles (see "Materials and Methods" for detail). A lateral pair of inner and outer labial sensilla is shown in Figure 3, where each of the processes of IL1, IL2, and OLL were identified and marked. The process of IL2 clearly accumulates the colloidal gold particles. Several other sections examined in the same way confirm the result. Since the structure of the entire nervous tissue has been ascertained on the basis of serial section electron micrographs, the identity of the cells recognized by 1 CB4 is now unambiguous. This in turn supports the reliability of the whole mount staining procedure, described earlier, that had led to the same conclusion.

The extent of the specificity of 1CB4 should be discussed here. We noticed consistently some small amounts of colloidal gold present in the processes of the amphid receptor neurons (AS in Fig. 3 ). With the whole mount staining procedure for light microscopy, there was no stain other than that of IL2 in front of the nerve ring, but we occasionally could see faint staining of some cell bodies or related structures behind the nerve ring. Since the amphid cell bodies are located behind the nerve ring, there is a possibility that 1CB4 has some weak affinity for these cells. The staining pattern, however, was usually poor and not reproducible; thus, we have not been able to identify the stained cells behind the nerve ring at the light microscopic level. In conclusion, it may be said that the specificity of 1CB4 is very high, at least among the cells in front of the nerve ring.

Specificity of 1 CB4 in male nervous tissue. Considerable differences have been observed between the nervous tissues of the hermaphrodite and the male in $C$. elegans both in the total number of the neurons (302 in the hermaphrodite versus 381 in the male) and in the gross anatomical structure (Sulston and Horvitz, 1977; Sulston et al., 1980, 1983; White et al., 1983; J. G. White, E. Southgate, J. N. Thomson, and S. Brenner, manuscript in preparation). They mainly arise from the cells used for mating and egg laying. We examined the staining pattern of 1CB4 for the male head (Fig. 4) and tail (Fig. 5) and found some extra cells stained that were absent in the hermaphrodite.

Figure 4 shows that, in addition to the six cells stained in a manner similar to those in the hermaphrodite head (numbered 1 to 6 in Fig.
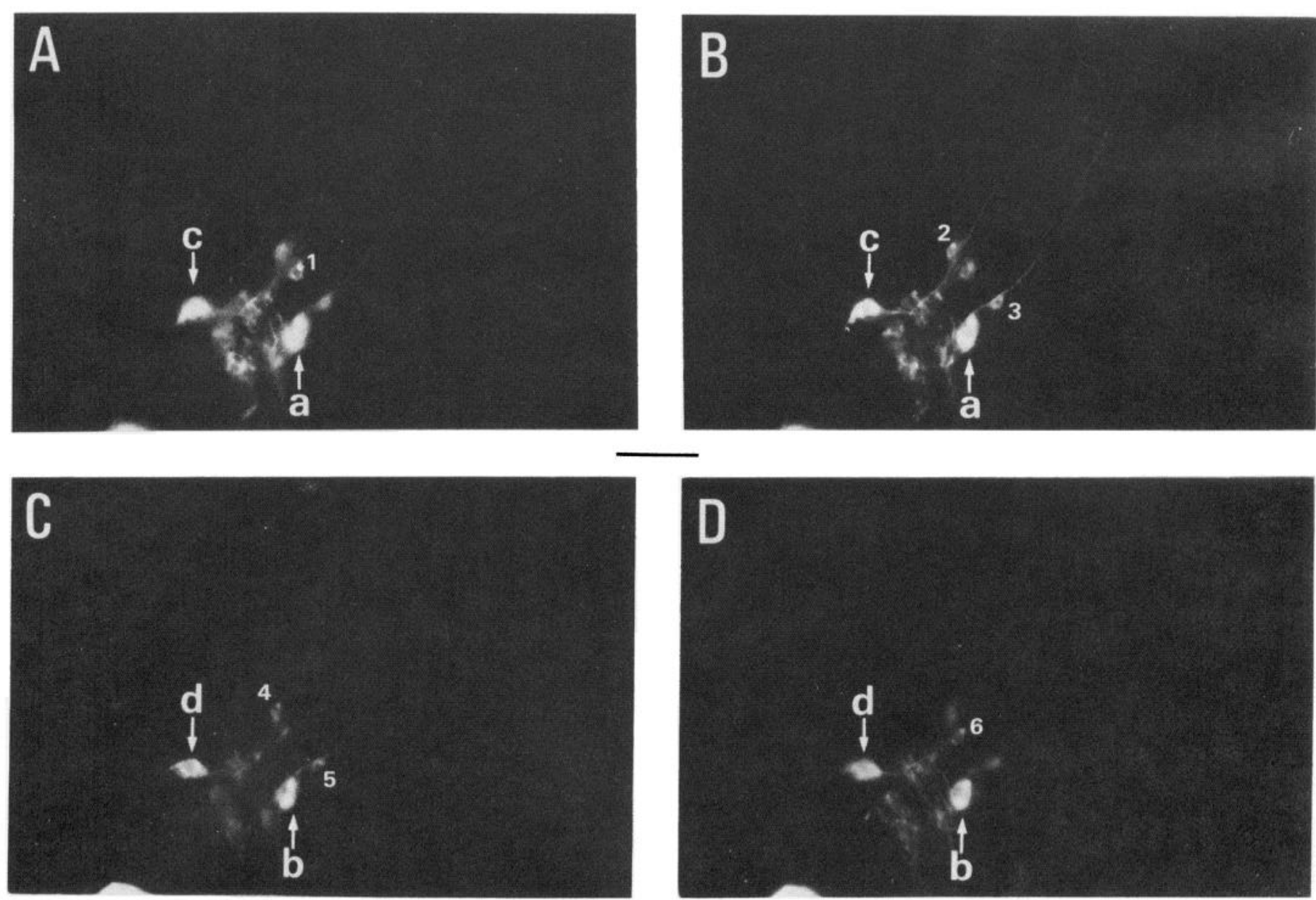

Figure 4. Immunofluorescent staining of a whole mount male head preparation with 1CB4. $A$ to $D$ represent four successive focal planes through the specimen, right side view. Numbers 1 to 6 represent six IL2 neurons, and labels a to $d$ represent four cephalic companion (CEM) neurons. Bar, $20 \mu \mathrm{m}$. 
4), four large cells can be seen labeled on four successive, different, focal planes (Fig. 4, $A$ to $D$ ); two (Fig. 4, arrows $a$ and $b$ ) are in front of and the other two (Fig. 4, arrows $c$ and $d$ ) are behind the nerve ring. From the analysis on the relative position of the nuclei of the stained cells (data not shown, but just as described for the hermaphrodite head in the previous section), we conclude that a group of six cells is IL2, whereas the four extra cells are CEM, the cephalic companions (Sulston and Horvitz, 1977). The conclusion is also supported by the fact that the CEM cells are present in the male head but not in the hermaphrodite (Sulston and Horvitz, 1977), and that the cell bodies of CEM are larger than those of IL2 (J. G. White, E. Southgate, J. N. Thomson, and S. Brenner, manuscript in preparation).

In whole mount preparations of male tails we can see some processes stained with 1CB4 on both sides of the tail (Fig. 5).
Besides the intestine, some cell bodies are also stained (out of focus) and, by changing focal plane, the stained processes can be traced up to these cell bodies in some instances. The total number of the labeled processes is eight on each side in this particular case but nine in two other preparations. The male tail possesses nine rays on each side that probably function as a mechano- and/or chemosensory organ during copulation; their detailed anatomy has been elucidated using serial section electron micrographs, and each of the 18 rays is shown to comprise two neurons and one structural cell (Sulston et al., 1980). The number, position, and orientation of these sensory rays suggest that the processes labeled in Figure 5 are those in the ray sensilla, but it cannot be determined at present which cell (or cells) of the three different classes is stained with 1 CB4.

There are some common structural features between the ray,
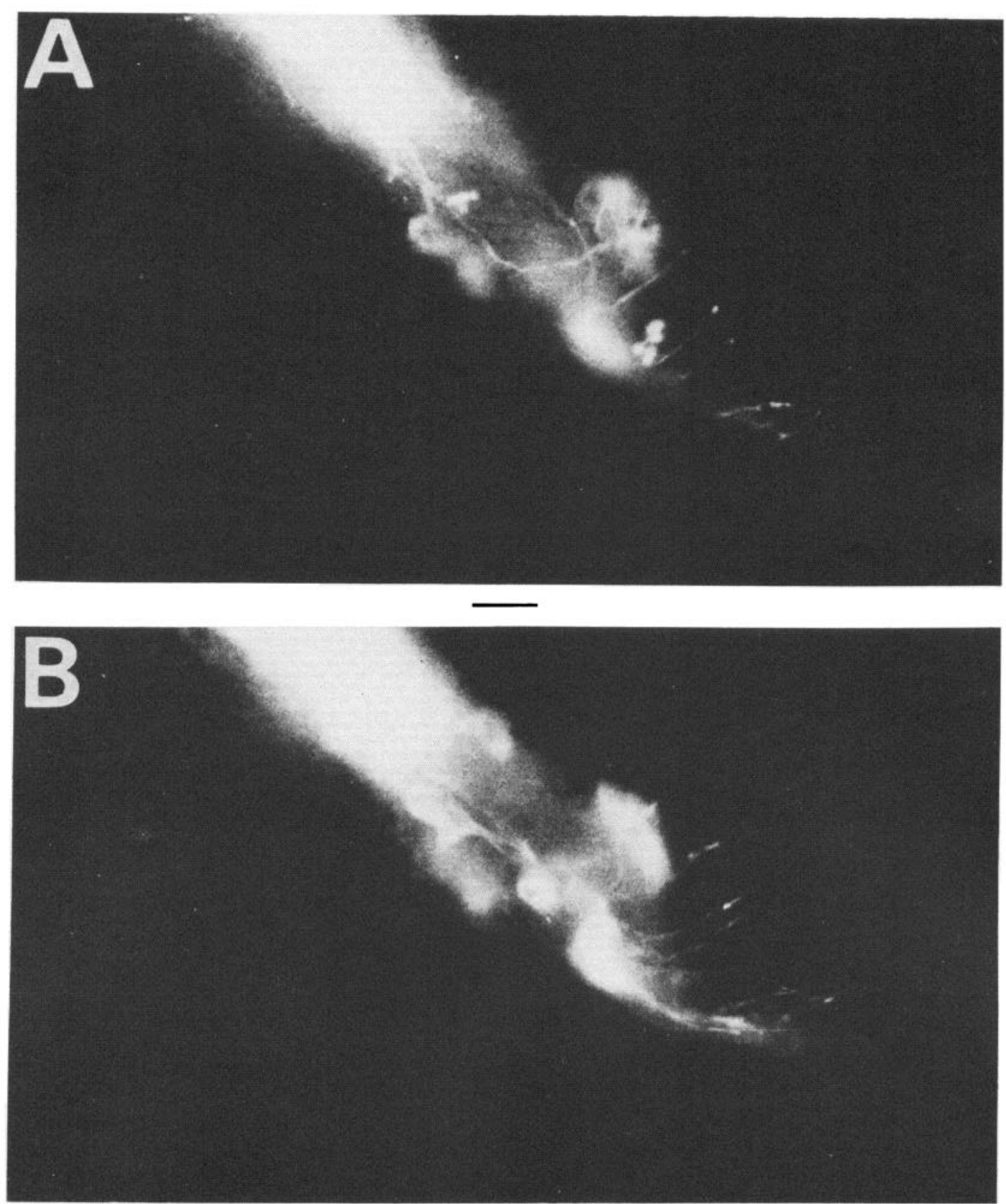

Figure 5. Immunofluorescent staining of a whole mount male tail preparation with $1 \mathrm{CB} 4 . A$ and $B$ represent two different focal planes. Note the fine processes stained. Bar, $10 \mu \mathrm{m}$. 

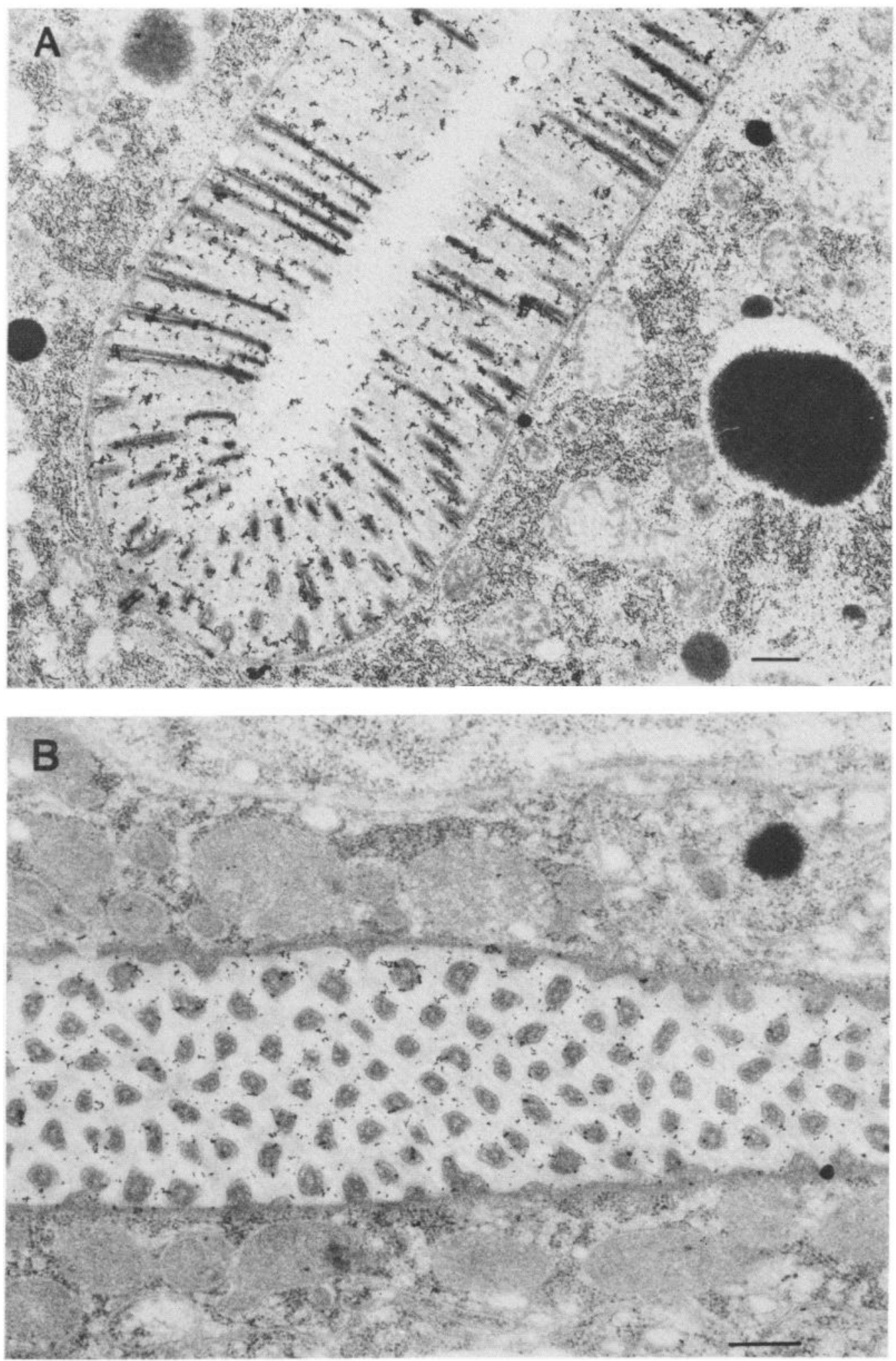

Figure 6. Immuno-gold staining of the intestine with 1CB4. Bars, 0.2 $\mu \mathrm{m}$ for both $A$ and $B$. See the text for details. inner labial and cephalic (of the male) sensilla. Each of the three sensilla consists of two different classes of neurons (RnA and RnB in the ray, (IL1 and IL2 in the inner labial, and CEP and CEM in the cephalic) and one sheath cell. Two neuronal processes run through the channel that is formed by the respective sheath cell and end in a different manner at the tip of the head or tail: one (RnA, IL1, or CEP, the presumptive mechanosensory neurons) lies beneath the cuticle whereas the other $(\mathrm{RnB}, \mathrm{IL} 2$, or CEM, the presumptive chemosensory neurons) penetrates to the exterior. The present study showed that 1 CB4 binds to IL2 and CEM, so that, by analogy, it is tempting to guess that $1 \mathrm{CB} 4$ may also label $\mathrm{RnB}$ in the ray sensilla.

Specificity of 1CB4 in other tissue. As noted in Table I, 1CB4 binds to the intestine and sperm. The pattern of the antigen distri- 


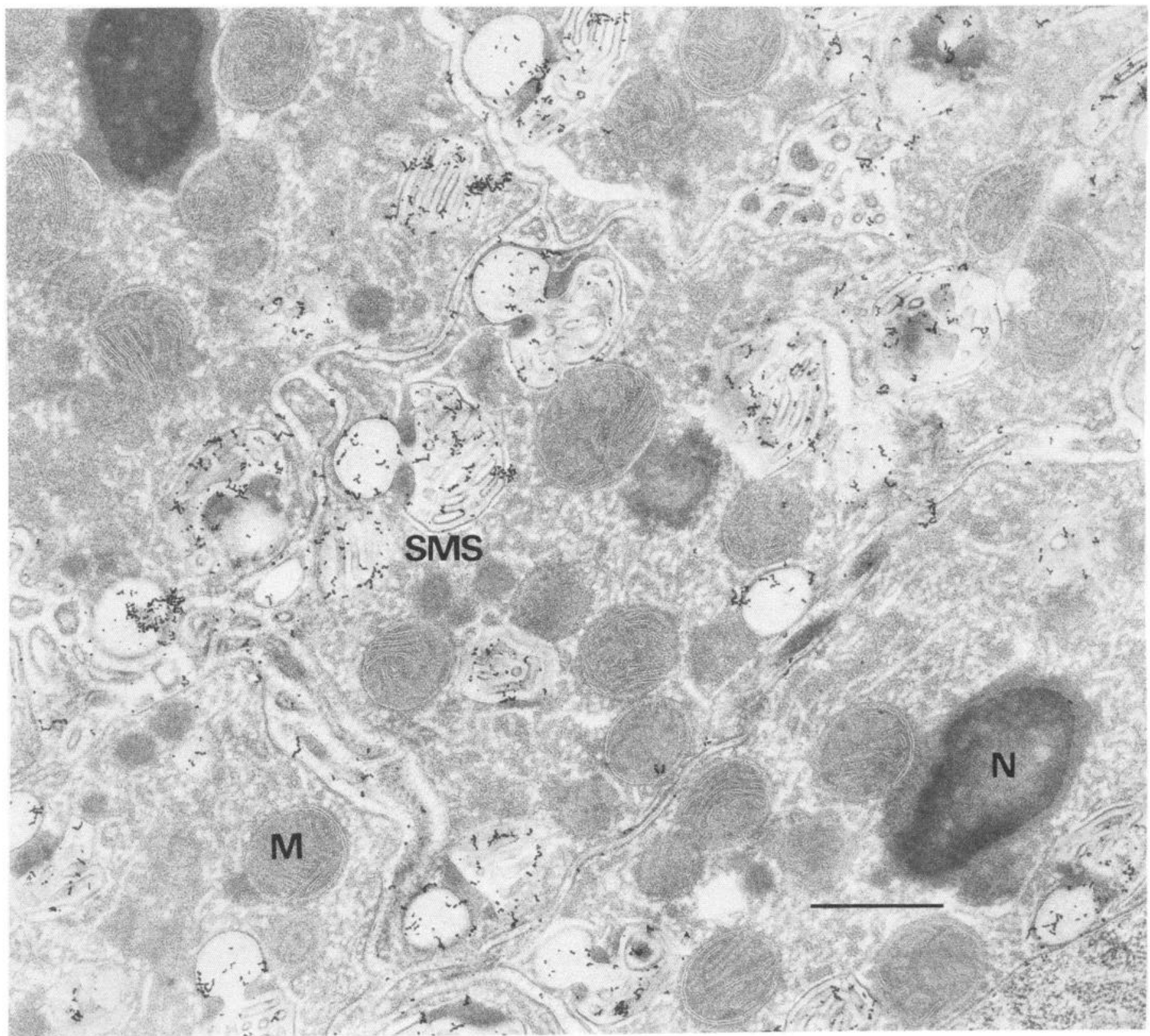

Figure 7. Immuno-gold staining of late spermatids with 1 CB4. The section was cut through the male gonad. $M$, mitochondrion; $N$, nucleus; SMS, special membrane structure. Bar, $0.5 \mu \mathrm{m}$. 
bution was examined in sections for the electron microscope as described earlier under "Specificity of 1CB4 in hermaphrodite nervous tissue" for the IL2 process.

Figure $6 A$ shows a transverse section of the intestine. The colloidal gold particles are present in the lumen of the intestine, especially around the region of microvilli. In Figure $6 B$ the section is transverse to the long axis of the villi. The gold particles tend to be distributed between the microvilli. It seems likely that 1CB4 binds to some materials secreted into the lumen of the intestine that is seen as the electron-lucent material between the microvilli in Figure 6 and/or the microvilli themselves.

A late spermatid is shown in Figure 7. It is clear that the gold particles are associated with the "special membrane structure" as designated by Wolf et al. (1978). The function of this structure is unknown, but it is reported to be formed by the association of a special vesicle with a fibrous body and in the mature sperm to fuse with the plasma membrane and empty part of its content to the exterior (Wolf et al., 1978). No colloidal gold particles were observed on the fibrous body (not shown).

It might be interesting to see whether there are any similarities between the cells with the common 1CB4 antigen in terms of the cell lineage that has recently been determined precisely in $C$. elegans (Sulston et al., 1983). The first few rounds of division of the zygote produce five somatic precursor cells (designated $A B, C, D, E$, and $\mathrm{MS}$ ) and one germ like precursor cell $\left(\mathrm{P}_{4}\right)$. The IL2 neurons, CEM cells, and ray cells are all derived from the $A B$ cell, whereas the intestinal cell and spermatid are from $E$ and $P_{4}$, respectively, indicating that some of the $1 \mathrm{CB} 4$ antigen-bearing cells diverge at the very early cleavage stage. In addition, there are no apparent common features among the subsequent lineage patterns that yield the different types of the 1CB4 antigen-bearing cells. It is therefore hard to imagine any possible lineage relationship between them at the moment.

Specificity of $1 C B 3$. 1CB3 binds to a pair of cells, the cell bodies of which are situated dorsolaterally at the level of the second bulb of the pharynx (Fig. 8). There are no cells other than the amphid sheath cells that have such a large cell body as shown in Figure 8 ( $A$ and $B$ ) in this region. The relative positions of the stained cells' nuclei (not shown) are consistent with this interpretation. The process of the amphid sheath cell forms a channel through which the amphid receptor neurons send their processes up to the tip of the head. In Figure 8 these processes are also shown to be labeled with 1CB3.

Sheath cells are components of sensilla (Ward et al., 1975) and are thought to support the associated neurons mechanically and/or chemically. On the basis of morphology, ultrastructure, and pattern of association with the respective neurons, they are put into seven classes: each has two to six members (total, 22 sheath cells). There seem to be no lineage relationships among these seven classes of sheath cells (Sulston et al., 1983). It is interesting that 1CB3 can discriminate just one class of the sheath cell population, indicating the presence of some specialization among the sheath cell classes.

\section{Appiication to mutants}

An obvious application of monoclonal antibodies against the nervous tissue in $C$. elegans is for screening mutants that have defects in the neuronal circuitry. As a preliminary attempt, we examined the staining pattern in the head of a mutant, CED3, in which the programmed cell death is totally blocked (Horvitz et al., 1982). It is expected in this mutant hermaphrodite that the CEM cells that die before hatching in the wild type hermaphrodite might survive and differentiate.

In fact, four extra cells were found to be stained besides six IL2 neurons with the monoclonal antibody 1CB4, just as in the case of the wild type male (Fig. 9, arrows a to $d$ ). The relative positions of the nuclei of these cells appear to correspond to those of the CEMs in the wild type male (not shown). It is interesting that the size of these extra cells in the CED3 hermaphrodite is relatively small in these preparations as judged from a comparison with the size of IL2
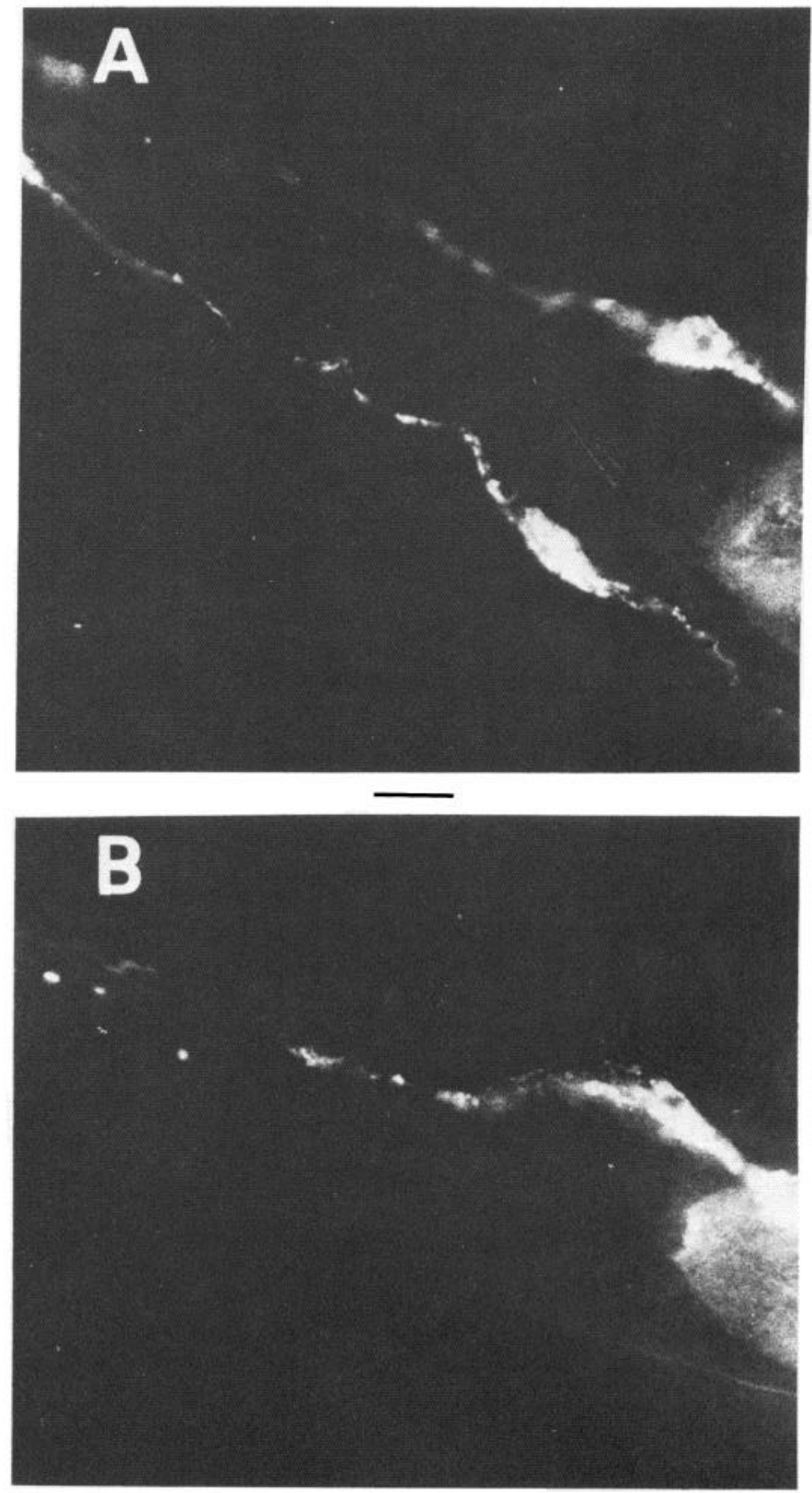

Figure 8. Staining of the amphid sheath cells with 1CB3. Two different whole mount head preparations are shown: $A$, a dorsoventral view, and $B$, a left lateral view. The second bulb of the pharynx is hardly seen in these pictures but is contiguous to the intestine that is also stained with 1CB3 (refer to the diagram, Fig. 1E). Bar, $10 \mu \mathrm{m}$.

(Fig. 9). In the wild type male the CEMs are much larger than IL2 (see Fig. 4).

Many mutants have been isolated that display a behavioral phenotype. They may be affected in chemotaxis (Ward, 1973; Dusenbery et al., 1975; Lewis and Hodgkin, 1977), thermotaxis (Hedgecock and Russell, 1975), touch avoidance (Chalfie and Sulston, 1981), or high osmolarity avoidance (Dusenbery et al., 1975). Screening of these mutants with monoclonal antibodies that bind specifically to different classes of neurons as described in this paper will allow rapid identification of the mutants which have defects in their neuronal circuitry; in some cases, a cellular basis for a specified behavior may become clear at this stage of analysis.

Finally, the analysis in serial section electron micrographs of the 

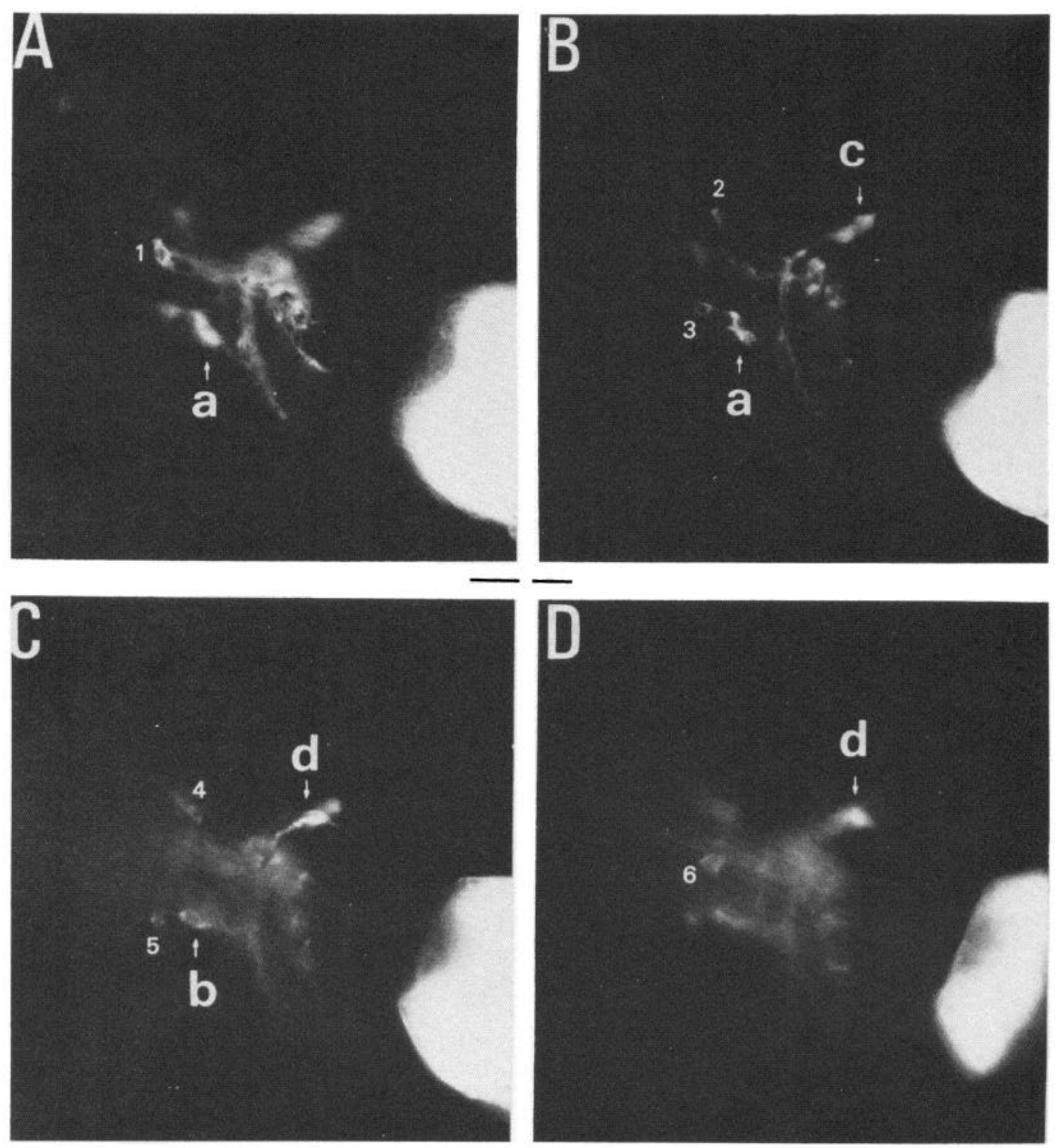

Figure 9. Staining of a whole mount hermaphrodite head preparation of a mutant CED3 with 1CB4. A to $D$, Four successive, different focal planes through the specimen. Numbers 1 to 6 represent six IL2 neurons, and letters a to $d$ represent four extra cells stained with 1 CB4. $20 \mu \mathrm{m}$.

\section{References}

Albertson, D. G., and J. N. Thomson (1976) The pharynx of Caenorhabditis elegans. Philos. Trans. R. Soc. Lond. (Biol.) 275: 299-325.

Albertson, D. G., J. E. Sulston, and J. G. White (1978) Cell cycling and DNA replication in a mutant blocked in cell division in the nematode Caenorhabditis elegans. Dev. Biol. 63: 165-178.

Barnstable, C. J. (1980) Monoclonal antibodies which recognize different cell types in the rat retina. Nature 286: 231-235.

Brenner, S. (1974) The genetics of Caenorhabditis elegans. Genetics 77: 71-94.

Chalfie, M., and J. Sulston (1981) Developmental genetics of the mechanosensory neurons of Caenorhabditis elegans. Dev. Biol. 82: 358-370.

Cohen, J., and S. Y. Selvendran (1981) A neuronal cell-surface antigen is found in the CNS but not in the peripheral neurones. Nature 291: 421423.

de May, J., M. Moevemans, G. Geuens, R. Nuydens, and M. De Brabander (1981) High resolution light and electron microscopic localization of tubulin with the IGS (immuno gold staining) method. Cell Biol. Int. Rep. 5: 889900.

Dusenbery, D. B., R. E. Sheridan, and R. L. Russell (1975) Chemotaxis defective mutants of the nematode Caenorhabditis elegans. Genetics 80 : 297-310.

Fujita, S. C., S. L. Zipursky, S. Benzer, A. Ferrus, and S. L. Shotwell (1982) Monoclonal antibodies against the Drosophila nervous system. Proc. Natl. Acad. Sci. U. S. A. 79: 7929-7933.

Galfré, G., and C. Milstein (1981) Preparation of monoclonal antibodies: Strategy and procedures. Methods Enzymol. 73: 3-46.

Gall, J. G., and M. L. Pardue (1971) Nucleic acid hybridization in cytological preparations. Methods Enzymol. 21: 470-480.

Hall, D. H. (1977) The posterior nervous system of the nematode Caenorhabditis elegans. Ph.D. thesis, California Institute of Technology, Pasadena.

Hawkes, R., E. Niday, and A. Matus (1982a) Monoclonal antibodies identify novel neural antigens. Proc. Natl. Acad. Sci. U. S. A. 79: 2410-2414.

Hawkes, R., E. Niday, and A. Matus (1982b) A mitochondrial marker for terminal neuronal differentiation defined by a monoclonal antibody. Cell 28: 253-258.

Hedgecock, E. M., and R. L. Russell (1975) Normal and mutant thermotaxis in the nematode Caenorhabditis elegans. Proc. Natl. Acad. Sci. U. S. A. 72: $4061-4065$.

Herman, R. K., and H. R. Horvitz (1980) Genetic analysis of Caenorhabditis elegans. In Nematodes as Model Biological Systems. Vol. I: Behavioral and Developmental Models, B. M. Zuckerman, ed., pp. 237-261, Academic Press, Inc. New York. 
Horvitz, H. R., H. M. Ellis, and P. W. Sternberg (1982) Programmed cell death in nematode development. Neurosci. Comment. 1:56-65.

Lewis, J. A., and J. A. Hodgkin (1977) Specific neuroanatomical changes in chemosensory mutants of the nematode Caenorhabditis elegans. J. Comp. Neurol. 172: 489-510.

McKay, R. D. G. (1983) Molecular approaches to the nervous system. Annu Rev. Neurosci. 6: 527-546.

McKay, R. D. G., and S. J. Hockfield (1982) Monoclonal antibodics distinguish antigenically discrete neuronal types in the vertebrate central nervous system. Proc. Natl. Acad. Sci. U. S. A. 79: 6747-6751.

Roth, J., M. Bendayan, and L. Orci (1978) Ultrastructural localization of intracellular antigens by the use of protein A-gold complex. J. Histochem. Cytochem. 26: 1074-1081.

Sternberger, L., K. W. Harwell, and N. H. Sternberger (1982) Neurotypy: Regional individuality in rat brain detected by monoclonal antibodies. Proc. Natl. Acad. Sci. U. S. A. 79: 1326-1330.

Sulston, J. E., and H. R. Horvitz (1977) Post-embryonic cell lineage of the nematode, Caenorhabditis elegans. Dev. Biol. 56: 110-156.

Sulston, J. E., D. G. Albertson, and J. N. Thomson (1980) The Caenorhabditis elegans male: Postembryonic development of nongonadal structure. Dev. Biol. 78: 542-576

Sulston, J. E., E. Schierenberg, J. G. White, and J. N. Thomson (1983) The embryonic cell lineage of the nematode Caenorhabditis elegans. Dev. Biol. 100: 64-119.

Vulliamy, T., S. Rattray, and R. Mirsky (1981) Cell-surface antigen distinguishes sensory and autonomic peripheral neurones from central neu rones. Nature 291: 418-420.
Ward, S. (1973) Chemotaxis by the nematode Caenorhabditis elegans: identification of attractants and analysis of response of use of mutants. Proc. Natl. Acad. Sci. U. S. A. 70: 817-821.

Ward, S. (1979) Nematode chemotaxis and chemoreceptors. In Taxis and Behavior, G. L. Hazelbauer, ed., pp. 141-168, Chapman \& Hall, London.

Ward, S., N. Thomson, J. G. White, and S. Brenner (1975) Electron microscopical reconstruction of the anterior sensory anatomy of the nematode Caenorhabditis elegans. J. Comp. Neurol. 160: 313-338.

Ware, R. W., D. Clark, K. Crossland, and R. L. Russell (1975) The nerve ring of the nematode Caenorhabditis elegans: Sensory input and motor output. J. Comp. Neurol. 162: 71-110.

White, J. G., E. Southgate, J. N. Thomson, and S. Brenner (1976) The structure of the ventral nerve cord of Caenorhabditis elegans. Philos. Trans. R. Soc. Lond. (Biol.) 275: 327-348.

White, J. G., E. Southgate, J. N. Thomson, and S. Brenner (1983) Factors which determine connectivity in the nervous system in Caenorhabditis elegans. Cold Spring Harbor Symp. Quant. Biol. 48: 633-640.

Wilcox, M., D. L. Brower, and R. J. Smith (1981) A position-specific cell surface antigen in the Drosophila wing disc. Cell 25: 159-164.

Wolf, N., D. Hirsh, and J. R. Mclntosh (1978) Spermatogenesis in male of the free-living nematode, Caenorhabditis elegans. J. Ultrastruct. Res. 63: 155-169.

Wood, J. N., L. Hudson, T. M. Jessel, and M. Yamamoto (1982) A monoclonal antibody defining antigenic determinants on subpopulations of mammalian neurones and Trypanosoma cruzi parasites. Nature 296: 34-38.

Zipser, B., and R. McKay (1981) Monoclonal antibodies distinguish identifiable neurons in the leech. Nature 289: 549-554. 